of hard carboniferous grit of a dark slate colour, except at the western end, where this rock is interspersed with red sandstone and shale and a few pockets of glacial drift. The beach between the foot of the cliffs and low water consists of rocks cut and furrowed by the action of the sea in perpetually rolling about the large boulders which lie along its surface.

Beyond Westward Ho the estuary of the Taw and the Torridge commences, consisting of a vast expanse of sand bounded by sand dunes.

Large fragments of rocks have in the course of ages been dislodged from the cliffs, the remains of which perpetually rolled about by the waves of the sea during high tides, which here rise to a height of 27 feet, have acted as instruments for grinding their fellows, and battering the cliffs, and so producing the rounded boulders which now strew the beach throughout its whole length for several miles, and a portion of which, drifted along the shore of the bay, have become finally heaped up in the Northam pebble ridge.

In some parts of the cliff indents of considerable size have been cut out, and across these the boulders have collected, and been thrown up into ridges and banks. At Abbotsham, about twelve miles from Hartland, there is such a bank, the top of which is 9 feet above high water of spring tides. This ridge or bank is about 160 feet wide, the boulders of which it is composed varying in size at the top from about 12 inches in length by 4 inches in diameter to pebbles 3 inches in diameter, the largest boulders weighing about 12 lbs, those at the foot reaching to a length of 2 feet and weighing about $70 \mathrm{lbs}$. Notwithstanding the large size of the boulders of which the bank is composed its sea face is shaped into a ridge and hollow, similar to other pebble ridges, the position of which varies according to the height of previous spring tides. The pebbles left on the shelf or hollow at the spring-tide level average a smaller size than those at the other part of the bank.

The boulders scattered along the beach all lie above the level of low water of neap tides. The general direction of movement is eastwards, but the boulders follow the line of the coast and the set of the flood tide. This direction varies round the bay from eastward to south-east, east again and then north-east, and finally south-east. The direction of the wind which drives the heaviest sea into the bay is from the north-west.

The Northam pebble ridge commences at the termination of the cliffs, and runs in a north north-easterly direction for upwards of two miles across a low flat plain which is below the level of high tides, until it falls into some hummocks of blown sand. It thus forms a natural embankment enclosing a tract of 900 acres of sandy and alluvial grass land which is used for grazing purposes, and also as golf links. After running along the foot of the sand hills for a short distance the pebble bank turns sharply to the south-east up the course of the outfall of the two rivers, the boulders diminishing in size to pebbles and coarse sand. There is an outlying bed of boulders, known as the Pulley, situated some distance from the bank, on the edge of the low-water channel of the river, but these appear to be a fixed deposit which neither in. creases nor diminishes in size.

The ridge is approximately 180 feet wide at the base and 20 feet high, the top being about 25 to 30 feet wide and 6 feet above high water of spring tides. The boulders on the top of the bank vary in size from about 12 inches.in length by 6 inches in diameter to pebbles an inch in diameter, the average size being about 8 inches in length by 4 inches in diameter, the largest being about $\mathrm{I} 2$ inches long and weighing from 40 to $50 \mathrm{lbs}$. At the foot of the bank are to be found boulders measuring from 15 to 18 inches in length and weighing from 100 to $150 \mathrm{lbs}$. The size of the boulders does not vary much throughout the length of the bank. The greatest collection of small stones appears to be on the shelf or hollow at the level of spring tides, where the pebbles vary from about half an inch to four inches in diameter. Some of the larger boulders have been drifted quite to the far end of the bank.

The boulders consist entirely of the same description of slatecoloured carboniferous grit as the cliffs from Hartland to Abbotsham are composed of, and there can be no doubt that they have drifted from this part of the coast. At the commencement of the ridge there are fairly numerous samples of shale and red sandstone pebbles from the cliffs between Westward Ho and Abbotsham, but these gradually disappear further along the ridge, the softer rock of which they are composed evidently not being able to withstand the constant grinding process produced by the wave action of the tides and wind. From the foot of the bank to low water the beach is covered with sand, which dries from a third of a mile at the south end to three-quarters of a mile at the northern end.

There is a very slow but continuous drift or movement of the boulders along the bank northwards. The progress of the ridge being stopped by the sand hills, the bank has bifurcated at this point, a new or double bank now forming, a circumstance which has occurred within the knowledge of those who have known the bank all their lives.

The boulders composing the ridge are in perpetual motion during the time that the bank is covered by the sea at spring tides. Even in calm weather in summer the whole face of the bank is continually changing under the influence of the wave action of the flood and ebb tide, which is of sufficient force to cause the movement of even large boulders. Observers who have carefully watched this movement and marked individual stones find that they are never in the same place two tides running, and each spring tide leaves its impress in a hollow and ridge at high-water mark.

In heavy on-shore gales these ridges and hollows are obliterated, and the face of the bank is pulled down seaward, the extent to which this is carried depending on the force and duration of the gale. After the storm, and when the height and force of the waves have subsided, the pebbles begin to move back again; the contour of the bank becomes more steep, and is soon restored to its normal condition.

During the winter at the end of 1896 there was a succession of westerly gales, culminating in a very heavy gale from the north-west. The bank was torn down and so lowered that the waves broke over it and inundated the enclosed land. Some of the largest boulders were thrown over the top of the ridge and hurled a considerable distance inland, where they now remain as a witness to the force of the gale. The disturbance of the boulders was so great under the action of the waves, that after the gale it was found that the base of the bank was moved ten yards inland, the clay bed on which it had rested previously being exposed. A somewhat similar movement took place during a gale about twenty years previously.

The peculiarity of this pebble ridge, and the way in which it differs from ordinary shingle banks, is in the large size of the boulders drifted along the coast, and heaped up by the action of the waves and tides.

\section{W. H. WHEELER.}

\section{RANDOM SELECTION.}

THIS memoir ${ }^{1}$ is the first of a series dealing with the problem of selection, namely the measurement of the changes in the characters of a race, when selection has acted upon any one, two, or more of them. The problem mathematically differs considerably according to the nature of the selection. But in all cases the general result is the same, the selection of any organ, whether by size, variability, or correlation with other organs, changes the sizes, variabilities, correlations of all other organs, whether directly correlated with the first organ, or only indirectly correlated with it owing to correlation with other organs which are correlated with the first organ. (A and C may have no correlation with each other, but both be correlated with $\mathrm{B}, e . g$. two parents in the absence of sexual selection and their offspring.) The chief types of selection which have to be treated independently are :- -

(i.) Random Selection or Sample Selection. - The isolation of a group out of a larger population. This will generally have characters divergent from those of the general population, but which form in themselves a correlated system of divergences.

(ii.) Epidemic Selection. - Selection which takes place so quickly that the growth or reproduction of the population may be neglected. For example, a severe winter or a pestilence.

(iii.) Auxetic Selection, or long-continued selection which allows during its action for growth, but not for reproduction. For example, diseases of childhood.

(iv.) Gonimic Selection, or long-continued selection which allows during its action for reproduction. For example, physical and mental qualities, pressure of other populations. These forms of

1 Contributions to the Mathematical Theory of Evolution. IV. On the Probable Errors of Frequency Constants, and on the Influence of Random Selection on Variation and Correlation, by Karl Pearson and L. N. G. Filon. (Royal Society, Nuv. 25, r897.)

$$
\text { No. } 1470 \text {, VOL. } 57]
$$


selection require very different mathematical treatment ; it is not at all clear, that they have always been sufficiently distinguished by writers on the theory of evolution. The above paper covers only the ground of the first kind of selection, random selection, but the memoir on epidemic selection is already completed, and the theory of the other cases advanced. The importance of random selection not only arises from the differentiation of species by isolation of small groups from a general population, but also from the fact that every measurement on a population is really a measurement on a more or less extensive random selection or sample. Hence the theory of random selection is also the theory of the probable errors of the frequency constants for any race. It enables us to determine the accuracy with which we have measured the chief racial constants.

Let the frequency-surface giving the distribution of a population with regard to $n$-organs be

$$
z=f\left(x_{1} x_{2}, x_{3} \ldots x_{n}, c_{1}, c_{2} c_{3} \ldots c_{q}\right)
$$

where $c_{1} c_{2} \ldots c_{q}$ are the $q$ constants which determine the charac ters of the population. Then the surfaces for the distribution of the errors in $c_{1}, c_{2} \ldots c_{q}$ is given approximately by

where

$$
z=z_{0} e^{-\frac{1}{2}\left(a_{11} e_{1}^{2}+2 a_{12} e_{1} e_{2}+\ldots\right)}
$$

$$
a_{v u t}=-\iiint \ldots z \frac{d^{2} \log z}{d c_{v} d c_{u}} d x_{1} d x_{2} \ldots d x_{n}
$$

Higher terms can be evaluated if needful; we have then a skew correlation of the system of errors. Approximately the divergences of any random selection from the characters of the general population form in themselves a normally correlated system, and we can predict from a knowledge of the divergence in one character the probable divergences in all the others.

The general formulæ are applied to the problems of

(i.) The random selection out of a population having n normally correlated organs,

If one character be changed, say the variability of one organ be altered, it is shown how the probable changes in all the other characters may be found; for example, the changes in the correlation of other organs. This is the death-blow to any theory that either variability or correlation can be constant for local races.

(ii.) Skew Variation, for all the three types discussed in a previous memoir.

Criteria are obtained for determining when skewness is significant; when the mode really diverges from the mean, \&c.

In many cases in which the normal curve of errors is used, the skewness is really significant, and thus many of the results used are illegitimate. For example, personal equation is generally sensibly skew, curves for size of organs during growth, and nearly all cases of botanical distribution.

These points are illustrated in the memoir by three numerical examples:-

(I.) Mitllerian glands in the legs of swine; data from the observations of two American naturalists. The skewness can be determined with less than 5 per cent. of probable error. It is therefore significant, and the use by the above-mentioned biologists of the ordinary theory of errors is in this case to be deprecated.

(II.) Enteric fever. Skewness is known to I per cent. of probable error.

The effect of raising mean age, or altering the incidence, \&c. on the character of the disease follows at once from the tables given.

(III.) Stature during growth; a critical case, taken because the distribution is almost normal. The skewness is, however, probably significant, and the influence indicated of random selection on stature during growth is in accordance with experience.

\section{MODIFICATION OF THE GREAT LAKES BY EARTH MOVEMENT. ${ }^{1}$}

THIE history of the Great Lakes practically begins with the melting of the Pleistocene ice-sheet. They may have existed before the invasion of the ice, but if so their drainage system is unknown. The ice came from the north and northeast, and, spreading over the whole Laurentian basin, invaded

1 Abridged from a paper, by Prof. G. K. Gilbert, in the National Geographic Magasine (September 1897 ).

NO. I 470 , vOL. 57.7 the drainage districts of the Mississippi, Ohio, Susquehanna and Hudson. During its wandering there was a long period when the waters were ponded between the ice front and the uplands south of the Laurentian basin, forming a series of glacial lakes whose outlets were sonthward through various low passes. A great stream from the Erie basin crossed the divide at Fort Wayne to the Wabash river. A river of the magnitude of the Niagara afterwards flowed from the Michigan basin across the divide at Chicago to the Illinois river; and still later the chief outlet was from the Ontario basin across the divide at Rome to the Mohawk valley.

The positions of the glacial lakes are also marked by shorelines, consisting of terraces, cliffs, and ridges, the strands and spits formed by their waves. Several of these shore-lines have been traced for hundreds of miles, and wherever they are thoroughly studied it is found that they no longer lie level, but have gentle slopes towards the south and south-west. Formed at the edges of water surfaces, they must originally have been level, and their present lack of horizontality is due to unequal uplift of the land. The region has been tilted towards the south south-west. The different shore-lines are not strictly parallel, and their gradients vary from place to place, ranging from a few inches to three or four feet to the mile.

\section{Early History of the Lakes.}

The epoch of glacial lakes, or lakes partly bounded by ice, ended with the disappearance of the ice-field, and there remained only lakes of the modern type, wholly surrounded by land. These were formed one at a time, and the first to appear was in the Erie basin. It was much smaller than the modern lake, because the basin was then comparatively low at the north-east. Instead of reaching from the site of Buffalo to the site of Toledo, it extended only to a point opposite the present city of Erie, and it was but one-sixth as large as the modern lake. Since that time the land has gradually risen at the north, canting the basin towards the south, and the lake has gradually encroached upon the lowlands of its valley.

The next great lake to be released from the domination of the ice was probably Ontario, though the order of precedence is here not equally clear. Before the Ontario valley held a landbound lake it was occupied by a gulf of the ocean. Owing to the different attitude of the land, the water surface of this gulf was not parallel to the present lake surface, but inclined at an angle. In the extreme north-east, in the vicinity of the Thousand Islands, the marine shores are nearly 200 feet above the present water level, but they descend southward and westward, passing beneath the lake level near Oswego, and towards the western end of the lake must be submerged several hundred feet. This condition was of short duration, and the rising land soon divided the waters, establishing Lake Ontario as an independent water body. The same peculiarity of land attitude which made the original Erie a small lake served to limit the extent of Ontario, but the restriction was less in amount because of the steeper slopes of the Ontario basin. Here again the southward tilting of the land had the effect of lifting the point of outlet and enlarging the expanse of the lake.

There is some reason to think that the upper lakes, Huron, Michigan and Superior, were at first open to the sea, so as to constitute a gulf, but the evidence is not so full as could be desired. When the normal lacustrine condition was established they were at first a single lake instead of three, and the outlet, instead of being south ward from Lake Huron, was north-eastward from Georgian bay, the outlet river following the valleys of the Mattawa and Ottawa to the St. Lawrence. The triple lake is known to us chiefly through the labours of Mr. F. B. Taylor, who has made extensive studies of its shore-line. This line, called the Nipissing shore-line, is not wholly submerged, like the old shores of lakes Erie and Ontario, but lies chiefly above the present water surfaces. It has been recognised at many points about Lake Superior and the northern parts of lakes Huron and Michigan, and measurements of its height show that its plane has a remarkably uniform dip, at 7 inches per mile, in a south-south-west direction, or, more exactly, S. $27^{\circ} \mathrm{W}$. The southward tilting of the land, involving the uplift of the point of outlet, increased the capacity of the basin and the volume of the lake, gradually carrying the coast-line southward in Lake Huron and Lake Michigan until finally it reached the low pass at Port Huron, and the water overflowed via the St. Clair and Detroit channels to Lake Erie. The outlet by way of the Ottawa was then abandoned, and a continuance of the 